\title{
BeCKett em SUa ÉPOCA / BeCKett EM NOSSA ÉPOCA
}

\section{S. E. GONTARSKI}

Logo após o centenário de nascimento de Samuel Beckett em 2006 e as comemorações sem precedentes realizadas em todo o mundo, em especial aquelas relacionadas ao teatro de Beckett, podemos olhar para trás e perceber que tal atenção é proporcional à reputação e à popularidade internacional do autor. Como testemunho, cito o início do resumo feito por Marjorie Perloff em seu discurso presidencial na Modern Language Association em dezembro de 2006, ano que passou a ser chamado de o ano de Beckett:

\begin{abstract}
Esse ano marca o centenário de nascimento de Samuel Beckett e tem sido maravilhoso acompanhar as comemoracões no mundo todo. De Buenos Aires a Tóquio, do Rio de Janeiro a Sófia, da África do Sul (onde Beckett não permitiu que suas peças fossem encenadas durante o Apartheid) à Nova Zelândia, da Universidade Estadual da Flórida em Tallahassee à Universidade de Reading, do Teatro Barbican em Londres ao Centro Georges Pompidou em Paris, de Hamburgo e Kassel e Zurique a Aix-en-Provence e Lille, de São Petersburgo a Madri e TelAviv, e, é claro, particularmente em Dublin, 2006 foi o Ano de Beckett. A maioria dos festivais incluíram não só encenações de suas peças, mas também palestras, simpósios, leituras, exposiçoes artísticas e mostras de seus manuscritos. No Festival PARIS BECKETT 2006, por exemplo, copatrocinado pelo governo francês e o Centro de Civilização e Cultura Francesa da Universidade de Nova York, foram apresentadas produções de toda a obra dramática de Beckett, encenadas em pequenos e grandes teatros espalhados por toda a capital francesa. Além disso, importantes personalidades, como os teóricos e romancistas Philippe Sollers e Helène Cixous, os dramaturgos Fernando Arrabal e Israel Horovitz, e o filósofo Alain Badiou, deram palestras. Para fechar com chave de ouro, em 2007 o Centro Georges Pompidou abrig[ou] uma importantíssima exposição sobre a obra de Beckett. (...) Quem, na verdade, pode ser considerado um artista mais universal que Beckett?
\end{abstract}

A ampla atenção dispensada à obra de Beckett em 2006 levantou, no entanto, diversos questionamentos, principalmente de longo prazo, a respeito da arte de Beckett para o século 21, para a nossa época. Para alguns, essa aparente adulação de um artista de teatro experimental indica um enfraquecimento da dimensão vanguardista de Beckett. A aceitação e celebração do autor pela ampla classe média, sendo considerado um dramaturgo "clássico", estudado em escolas e listado entre os autores fundamentais, denotaria um adestramento, uma domesticação, e até mesmo um aburguesamento de sua obra. Essa aceitação suscita questionamentos: perde-se algo devido a essa popularização da vanguarda? E caso alguns ingredientes essenciais da arte de Beckett se percam no processo de abertura ao grande 
público, serão eles recuperáveis? Em outras palavras, a dimensão vanguardista da obra de Beckett é recuperável?

A seguir, examino a forma como alguns artistas - os brasileiros Fernando e Adriano Guimarães, o cineasta canadense Atom Egoyan, JoAnne Akalaitis, que já foi apóstata de Beckett, e Christopher McElroen, que levou sua montagem de Esperando Godot, originalmente produzida para o Teatro Clássico do Harlem, para as ruas do $9^{\circ}$ Distrito de Nova Orleans ainda devastadas após a passagem do furacão Katrina em 2005 - vêm recuperando algo das raízes vanguardistas de Beckett e assim revitalizando uma tradição teatral experimental que poderia ficar historicamente presa na França e Europa do pós Segunda Guerra Mundial. Assim, essa recuperação evita que se reduza a arte de Beckett a cópias xerox de produções anteriores, mesmo que essas sejam as mais facilmente sancionadas pelo draconiano Beckett Estate (os executores do espólio literário beckettiano). Alguns podem alegar (e já o fizeram) que essa recuperação prejudica a reputação da obra e consequentemente do autor, visto que ela implica repensar o texto beckettiano em certa medida. Aqui essa posição protecionista étotalmente rejeitada. O que proponho, ao contrário, é que a recuperação do vanguardismo de Beckett não apenas revitaliza um teatro que já tem mais de 50 anos, mas também que esse redirecionamento vanguardista não é necessariamente conflitante com a aceitação de Beckett como "clássico", ou até mesmo como um dramaturgo canônico, e consequentemente demonstra a vitalidade contemporânea da obra de Beckett. Ou seja, ele é um autor muito vinculado à sua época, e também à nossa.

Artistas como os irmãos brasileiros Fernando e Adriano Guimarães e os colaboradores de seu coletivo teatral, JoAnne Akalaitis, o cineasta e artista plástico Atom Egoyan, e Christopher McElroen, por exemplo, não só "dirigem" a obra de Beckett. Eles também a redirecionam para suas raízes imagísticase dessa forma restauram sua dimensão experimental e até mesmo política. Um Beckett de vanguarda, essa é a minha proposta, um Beckett para o século 21 - e talvez além.

\section{Atom Egoyan: Steenbeckett}

Uma possibilidade dinâmica para que se mantenha a vitalidade das encenações da obra de Beckett no futuro é aquela proposta pelo cineasta canadense, nascido no Egito, Atom Egoyan. Egoyan dirigiu uma montagem tradicional de A Última Gravação de Krapp, com John Hurt, para a série Beckett on Film, uma tentativa ambiciosa de registrar a longa e elogiada turnê do Gate Theater, na qual todas as 19 peças para o palco foram encenadas. Logo em seguida, Egoyan usou o filme completo como peça central de seu próprio trabalho artístico, uma instalação no Museu do Homem em Londres que desdobrava apresentações contínuas do filme, em perspectivas alteradas, antitéticas, no contexto de uma exposição mais ampla, adaptada àquele espaço, sobre memórias gravadas que Egoyan denominou Steenbeckett. A obra de Egoyan - assim como a de Beckett - tinha como foco a memória, a sua preservação, distorção e recuperação. Os participantes entravam no Museu do Homem, atualmente abandonado, passavam por um labirinto escurocom vários caminhos, subiam escadas, passavam por túneis, por objetos descartados, tais como máquinas de escrever, vitrolas, discos, "rooolos" de fita magnética de áudio, pilhas de fotografias em deterioração, os detritos da memória. 
Enfim chegavam a uma sala de projeção mal acabada e assimétrica onde a versão comercial de Egoyan de $A$ Última Gravação de Krapp era projetada para uma pequena plateia - 10 a 12 espectadores por vez - que assistia ao filme sentada em um banco improvisado, a uma distância de menos de dois metros da imensa parede onde o filme era projetado, o que tornava a imagem granulada e embaçada. As enormes imagens do filme faziam com que os espectadores parecessem anõesque tivessem descoberto ou se deparado como que parecia ser mais um objeto cultural descartado. Dali, os espectadores iam para outro cômodo, alguns antes mesmo de o filme acabar, outros permaneciam sentados até o fim e assistiam ao filme mais de uma vez, à espera de algum sinal que indicasse que deveriam seguir adiante. Na sala seguinte, a plateia entrava no próprio ambiente do filme, onde, de acordo com as informações do programa, 600 metros de filme passavam contínua e ruidosamente por rolos, para cima e para baixo, para frente e para trás, dentro e à volta de todo o cômodo, do teto ao chão, de parede a parede, uma vez atrás da outra, sem parar, rodeando, abraçando, engolfando, submergindo o espectador. Por fim, a plateia passava por uma antiga mesa de edição Steenbeck no fundo do cômodo, onde a imagem era visível em miniatura, uma imagem flagrada pelo lado errado de um telescópio, observada através da cama de gato formada pelo filme que ruidosamente ia passando. A obsoleta máquina de edição Steenbeck foi o equipamento utilizado por Egoyan para editar seu filme, A Última Gravação de Krapp. O equipamento analógico tinha a aparência exata de antiguidade desajeitada que Egoyan parecia querer dar a seu filme. Tão importante quanto o filme, com sua materialidade esuas imagens agigantadas e miniaturizadas, era o próprio equipamento de edição. Central à visão de Egoyan de $A$ Última Gravação de Krapp, tornou-se a peça central de sua instalação, da mesma forma que o gravador de rolo havia sido na peça de Beckett. A peça A Última Gravação de Krapp era então mais uma relíquia em processo de deterioração, o filme comercial, algo como o Beckett autêntico, agora ele mesmo uma peça de museu que aos poucos desvanece, Beckett congelado no tempo, mas desdobrado no trabalho de Egoyan e assim, simultaneamente, uma obra de arte de um frescor impressionante.

Quando Egoyan novamente voltou sua atenção para Beckett, potencializou ainda mais o papel da tecnologia em sua montagem de Eh Joe. Para o centenário, o incansável Michael Colgan convenceu o Beckett Estate a ceder os direitos para a encenação da telepeça e, por sua vez, Colgan convenceu o cineasta canadense Atom Egoyan a dirigir Beckett novamente. Com uma atuação de Michael Gambon que era um verdadeiro tour de forcee Penelope Wilton como a Voz, a montagem foi certamente um dos pontos altos (talvez tenha sido o apogeu) das celebrações do centenário de Beckett no Teatro Dublin Gate em abril de 2006. Em seguida, a produção do Teatro Gate mudou-se para o West End de Londres para uma série de trinta apresentações, de 27 de junho a 15 de julho de 2006.

A adaptação (ou transformação) de Egoyan era potencialmente binária, uma produção híbrida de palco e vídeo "ao vivo", com o palco dividido em duas partes: parte da frente e parte de trás, em vez de esquerda e direita como é comum nas encenações da telepeça. Dessa forma, se criava não uma divisão de mídias, mas uma justaposição que criava um palimpsesto de Joes. De início, embora não desse para perceber, ele já estava separado da plateia por uma tela muito fina, quase imperceptível (ela mesma um eco ou metáfora da tela da televisão), na qual sua imagem era projetada quando a Voz começava seu ataque. A concepção de Egoyan, 
com sua tecnologia híbrida de trabalho cênico, televisão e filme, possibilitava uma tradução sem costuras do trabalho televisivo com o palco. Nas duas produções do próprio Beckett, a câmera se move na direção de Joe em nove investidas, a imagem física da intensidade crescente do ataque da Voz e a confirmação da interioridade do conflito eram conspícuos, quase desastrados, à medida em que a câmera fisicamente avançava na direção de Joe. Mas o uso de Egoyan de um zoom computadorizado, cujo movimento era imperceptível, adicionava dimensões de mistério à peça. Algo fantasmagórico, semelhante a uma aparição, estava em curso, ao vivo, ali no palco. O movimento da câmera era imperceptível, mas em determinado momento os espectadores se davam conta de que estavam, de repente, vendo um close mais intenso de Joe, de que estavam quase dentro de sua cabeça; aquilo que era antes o corpo completo de Joe deitado em sua cama, com o rosto visto em três quartos, agora era apenas um rosto.

Pode-se criticar a encenação de Egoyan alegando que ele a dirigiu como se Beckett nunca tivesse, ele mesmo, dirigido (e revisado) o texto, e assim Egoyan teria trabalhado com um texto que o próprio Beckett havia considerado inacabado. Como explicou em detalhes e repetidamente para seu diretor americano Alan Schneider em 7 de abril de 1966, Beckett acrescentou um sorriso à última imagem de Joe. Dessa forma, o autor modificou não só a imagem visual final da peça, mas também o seu significado: "Em Londres e Stuttgart eu pedi um sorriso no final (ah, não um sorriso real). Ele 'ganha' de novo. Então ignore a rubrica 'A imagem se esfuma, a voz como antes'. O rosto segue totalmente presente até o último $E$ h, Joe. Depois, sorriso e lento fade out". (Harmon 202). Como resultado de suas encenações, Beckett também simplificou a apresentação da voice-over final: "Decidi que frisar certas palavras no final era muito difícil para o ator e não era bom. Então, simplifiquei o penúltimo parágrafo [...]”. Beckett fez outra modificação que só poderia ser resultado dos aspectos práticos da encenação: “Em Londres, o único som além da voz era o das cortinas, e do abrir e fechar da janela, porta e armário. Mas em Stuttgart, adicionamos o som de passos quando ele se move e tornamos isso interessante fazendo-o usar uma meia quase saindo de um dos pés e o outro pé calçado com meia e chinelo. A meia quase saindo porque no início ele estava tirando a meia para ir se deitar quando foi interrompido pela repentina ideia ou súbita sensação de que estava ouvindo um barulho e deveria fazer uma última ronda para verificar se estava tudo bem". Para Beckett, a chave do desfecho, que foi descoberta e tomou forma durante a encenação, era Joe conseguir sufocar a Voz: "Sorriso bem no final, quando a voz para (tendo conseguido mais uma vez). A encenação de Egoyan foi surpreendente, com o magnífico rosto envelhecido de Gambon e seus dedos de pianista, mas também sugere que ainda há muito a ser descoberto neste texto que se tornou uma nova peça para ser encenada. Essa montagem tão visual de Egoyan evocava algo do poder vanguardista dessa obra (e portanto também de Beckett).

\section{JoAnne Akalaitis}

JoAnne Akalaitis foi quase banida para sempre por causa das liberdades que tomou em sua montagem de Fim de Partida, realizada em 1984 no Teatro Americano de Repertório da Universidade de Harvard (ART). Ela pareceu se redimir cerca de 24 anos depois graças à 
encenação de uma série de peças curtas, um espetáculo destinado a atrair atenção em Nova York, tanto pelo ator principal, quanto pela diretora e pelo autor. Celebrado, reverenciado, tratado como celebridade, o bailarino Mikhail Baryshnikov protagonizou as quatro peças curtas, que estrearam em dezembro de 2007 no New York Theatre Workshop. O conjunto de quatro peças curtas incluía duas peças mudas, Ato sem Palavras I e II, Esboço para teatro II e Eh, Joe, uma peça para televisão que, depois da montagem de Egoyan, passou a fazer partedo repertório de peças para o palco. Os dois Atos sem Palavras constituem um par inevitável, e Akalaitis tirou provei toda graciosidade angelical de Baryshnikov. Mas a junção feita na segunda metade do espetáculo realçava como a costura das peças breves não pode, nem deve ser arbitrária.

No palco, Eh, Joe é uma das peças curtas de Beckett que, sozinha, se basta para a noite toda, como ficou evidente na produção de Egoyan em Dublin. Lá, nada a antecedeu; nada a sucedeu. Akalaitis apresentou sua versão como parte de um agrupamento de um quarteto e os amarrou em um conjunto consistente, mas a decisão de cobrir o palco com cerca de 15 centímetros de areia só fazia sentido na primeira metade do quarteto. Como afirmou o crítico de teatro do New York Times, Ben Brantley, a respeito da performance de Baryshnikov, "durante o resto do espetáculo, podia-se notar a boa e velha física segurando pés que antes voavam como nenhum outro jamais o fez" (19 de dezembro de 2007). Porém, havia mais que a gravidade e a idade agindo sobre Baryshnikov que dançava em uma praia. Embora funcionasse de forma soberba para o Ato sem Palavras, $I$, a areia tornava a movimentação no palco quase impossível nas três peças subsequentes, e talvez tenha sido essa a intenção de Akalaitis. A cadeira de rodas em Esboço para teatro II, por exemplo, ficou imobilizada, e assim evocava, talvez até mesmo ecoasse, pelo menos visualmente, a imobilidade de Dias Felizes. Joe, então, não conseguia se mover em seu quarto e impedir que fosse invadido pelos olhares indiscretos. Mas Akalaitis tirou proveitodo que parecia ser um problema, filmando e projetando os movimentos de Eh, Joe como um conjunto múltiplo de imagens, em uma variedade de tamanhos, em uma variedade de telas. Na verdade, esse gênero híbrido, parte teatro ao vivo e parte filme "ao vivo", técnica que Egoyan também utilizou em sua montagem de Eh, Joe, era central nas quatro peças, usada não só para criar um grande efeito individualmente, mas também uma continuidade entre as peças, baseada nas múltiplas imagens projetadas e, portanto, em múltiplas perspectivas simultâneas. A decisão de direção mais questionável talvez tenha sido a de criar uma presença corporal para a voz de Joe, interpretada por Karen Kandel sob a luz de um refletor. Isso, juntamente com a música de Philip Glass (uma presença constante em todo a obra de Akailitis), é exatamente o tipo de escolha que ocasionou tanto estardalhaço em sua montagem de Fim de Partida em 1984. Equívocos conceituais à parte, Akalaitis ao final transformou uma coleção improvável de peças curtas em uma noite caleidoscópica e coesaque superou (na sua maioria) a desvantagem autoimposta da gravidade potencializada pela areia. Como Brantley inteligentemente observou, "esse enraizamento de um bailarino alado captura de forma comovente as duras leis do universo de Beckett, no qual a Mãe Terra nunca para de puxar as pessoas na direção do túmulo". Mas o quarteto de peças curtas de Akailaitis era mais que Baryshnikov. Ele sugeria o redirecionamento de Beckett na direção da vanguarda com uma montagem mais ou menos tradicional e ainda assim inteiramente nova. 


\section{Adriano e Fernando Guimarães}

Tratar um texto de Beckett ou uma montagem como um objeto encontrado, como fez Egoyan em Steenbeckett, é central à estética dos irmãos Guimarães, artistas plásticos sediados em Brasília e fundadores da Companhia Teatral Gabinete ${ }^{3}$. Eles vêm mantendo um diálogo incessante e em constante evolução com a obra de Beckett desde seu primeiro espetáculo, Felizes para Sempre, que incluía diversas versões de Dias Felizes (Happy days), Ir e Vir (Come and go), Jogo (Play) e Balanço (Rockaby). O espetáculo ficou em cartaz, em diversos lugares, quase todos no Brasil, de 1998 a 2001.

Cada peça era precedida por e entremeada com trabalhos dos próprios Irmãos Guimarães, chamados por eles de performances, normalmente uma instalação que constituía uma variação de um tema retratado na peça de Beckett. A abordagem deles então é combinar teatro, arte performática, música, pintura, escultura e literatura em uma forma artística composta e híbrida e também colaborar com artistas contemporâneos de destaque, em sua maioria brasileiros. Em Felizes para Sempre (Happy days), por exemplo, eles trabalharam com a artista plástica Ana Miguel, responsável pelos figurinos e objetos de cena, com o fotógrafo e iluminador Dalton Camargo, com a curadora Marília Panitz e com as atrizes convidadas Vera Holtz, como Winnie em Dias felizes, e Nathalia Timberg - substituída posteriormente por Vera Holtz - como Mulher, a Mulher na Cadeira de Balanço, M, em Balanço (Rockaby). Uma segunda instalação Não ficamos muito tempo... juntos, apresentada em diversas configurações entre 2002 e 2003, foi construída em torno de Respiração e incluía quatro outras peças: Catástrofe, Ato sem Palavras II, O que onde e Jogo. A terceira personificação do diálogo dos Irmãos Guimarães com Beckett foi construída em torno de Todos os que Caem, novamente entremeada com seus próprios vídeos, fotografias, objetos e performances, e incluía Balanço, Eu Não, Rascunho para Teatro II e Pedaço de Monólogo. Essas três antologias encenadas em um período de seis anos constituem a trilogia multimídia de espetáculos. Foram diversas manifestações que ligaram as obras teatrais de Beckett a espaços públicos mais amplos, além dos confins do teatro. Esse trabalho constituía, em concepção e execução, o extremo oposto do projeto Beckett on film que tomava forma quase exatamente ao mesmo tempo na Europa.

Não houve duas representações do projeto dos Irmãos Guimarães que fossem iguais. A fim de manter o frescor e evitar automatismos, os atores frequentemente trocavam de papel. A arte dos Irmãos Guimarães resistiu à previsibilidade e resiste a ser reduzida a uma homenagem, que era o objetivo do projeto dos filmes, ao que tudo indica.

Como afirmou a crítica de arte Vitória Daniela Bousso, "no trabalho de Adriano e Fernando Guimarães, a transição do visual ao teatral constitui um espaço híbrido, um território de complexidades regido pela experimentação". Como seu trabalho se concentra no corpo humano, eles acionam diretamente os jogos culturais de regulação e controle a que estão submetidos. Para os Irmãos Guimarães, o corpo é menos ancilar do que, em geral, seria na obra de Beckett e se torna o lugar do combate das relações de poder - um tema que se não é expresso abertamente na obra de Beckett, certamente é um subtexto.

De acordo com o historiador da arte Nicholas Oliveira, "o corpo interpreta ou desempenha um personagem, mas simultaneamente representa a si mesmo, se afirma como receptáculo do subconsciente. Em outras palavras, o corpo, em uma instalação, desempenha 
um papel bem definido: dar acesso ao que é instável e efêmero. A ação imprevisível do corpo sempre oferece uma possibilidade de ruptura e desestabilização na obra pós-moderna". Tanto na obra de Beckett quanto na de Adriano e Fernando Guimarães, o corpo funciona mais como uma máquina do que como asede de sentimentos, pensamentos, ou mesmo de identidade. Em muitos aspectos, o teatro dos Irmãos Guimarães é um teatro de não pensamento, assim como o de Beckett.

As obras de Beckett são, então, tratadas como ready-mades pelos Irmãos Guimarães, como objetos a serem colocados dentro de seus próprios ambientes construídos. Assim, Beckett não necessita de revisão profunda ou renovação nesta recuperação deseu vanguardismo. Suas obras - precedidas e sucedidas por imagens que os Irmãos Guimarães criam a partir de sua visão de Beckett - são persistências de imagens dos textos do próprio Beckett. Elas são, então, menos uma crítica da obra de Beckett, do que espectros ou fantasmas dela. É um redirecionamento total da obra beckettiana, em um duplo movimento de retorno às suas raízes vanguardistas e de avanço na direção de um novo século de arte performativa. $\mathrm{O}$ que se obtém de Beckett dessa forma é tanto o resultado de seus ambientes tomados por instalações quanto uma parte intrínseca da própria obra do autor e, assim, as obras de Beckett adentram, sem adulteração, um novo espaço poético, tornam-se parte de uma nova poética. Os Irmãos Guimarães criam seu próprio arquivo beckettiano: Beckett em um, ou visto como um, armário de curiosidades, um Beckett composto de fragmentos culturais.

O uso antifônico que os Guimarães fazem das obras e palavras de Beckett é um bom exemplo. Sua abordagem de Respiração, ou suas variações, é apresentada em conjunto com diversas instalações por eles chamadas de Respiração + (Respiração mais, ou imagens d'après Beckett, ou imagens beckettianas persistentes). Embora apresentadas juntamente com outras peças mais conhecidas, a modesta Respiração assume aqui o papel de uma obra de destaque, em que uma de suas versões apresenta um ator nu dentro de uma caixa de acrílico e, acima dela, um outro ator ou atriz dá uma palestra sobre o significado da respiração. A caixa começa a ficar embaçada com o dióxido de carbono enquanto o humano é reduzido à maquinaria da respiração, homem ou mulher reduzido(a) a uma função metabólica. $O$ ator dentro da caixa começa a ficar ofegante, tentando respirar, e bate na caixa desesperado. A pessoa que discursa (Vera Holtz na montagem a que assisti) não percebe o sofrimento humano já que está totalmente concentrada em sua tarefa: dar sua palestra, descrevendo os detalhes do processo respiratório. Dessa forma, Respiração é dramatizado de uma forma impactante, sem alterar absolutamente nada do texto de Beckett.

Outras montagens de Respiração + apresentam um ator (ou atores) submersos em água, reagindo a uma campainha autoritária e aparentemente arbitrária que comanda e controla suas submersões e reemersões, controlando, portanto, sua respiração. Em outra versão de Respiração + , comumente utilizada como entreato das próprias peças, atores afundam a cabeça em baldes de água quando soa a campainha e só podem voltar a respirar quando a campainha toca novamente. Em outra ainda, um único ator vestido está totalmente submerso em um gigantesco aquário, e a duração dessa submersão é controlada pela campainha. Em uma terceira imagem, um ator submerso, novamente vestido, está todo contorcido, de forma grotesca, dentro de uma banheira e é visto de cima. A respiração do ator parece sujeita a, ou controlada por, uma força externa e arbitrária, neste caso um sino ou uma campainha, mas 
poderia igualmente ser um apito ou um cutucão, como nos dois Atos sem Palavras, ou a campainha estridente de Dias Felizes, obras que os irmãos encenaram como parte de seu constante diálogo com Beckett.

Grande parte do trabalho dos Irmãos Guimarães transborda do teatro para o espaço da galeria (ou sai da galeria e volta para o teatro), Respiração + pode ser visto como prelúdio dramático, entreato ou poslúdio. A ampliação do espaço cênico para uma galeria, um pátio, ou uma rua enfatiza a ideia de um espaço expressivo amplo, uma utilização diferente do espaço teatral não mais visto como mero pano de fundo.

Outra série de performances é intitulada $L u z$ - e $L u z+$. Aqui, o poder (em grande parte em forma de energia elétrica) é transferido para uma plateia participante em que os espectadores acendem e apagam interruptores para controlar o ritmo da ação na performance. Dessa forma, o corpo da plateia, ou os corpos dos espectadores, integra-se à performance tornando a plateia cúmplice da luta pelo poder. A atuação é frenética, com os atores correndo ou pulando no lugar, muitas vezes até a exaustão, enquanto a luz está acesa, e cessando o esforço quando a luz se apaga. Assim, os membros da plateia determinam autocraticamente a duração do esforço.

Dupla Exposição é uma instalação composta de quatro ambientes com as palavras de diversas peças curtas de Beckett projetadas ou físicamente coladas às paredes, janelas e caixas transparentes. As próprias palavras de Beckett, como objetos materiais, são apresentadas dentro de caixas, como pequenos armários de curiosidades, o precursor do século XVIII daquilo que hoje chamamos de museu. Todas as portas de vidro da entrada da galeria estão inteiramente cobertas com textos de Samuel Beckett. Ao entrar, o espectador se encontra no primeiro ambiente: uma antessala retangular quase escura, demarcada por vidraças, onde também foram escritos fragmentos de textos. Em cada extremidade dessa sala, há fotografias em tamanho real do personagem que aparece ao longo de toda a exposição. As fotos são quase idênticas, mas revelam o personagem sob a ação de duas luzes contrastantes: uma excessivamente clara e outra escura demais. Ambas conferem à imagem uma dimensão evanescente. Ou seja, aquilo que aparentemente vemos como algo real é decididamente uma imagem (como Henri Bergson vem nos relembrando, pelo menos desde Matéria e Memória), ou a persistência de uma imagem. Seu aparecimento ou desaparecimento são controlados pela luz, que, por sua vez, é controlada pela eletricidade, que, por sua vez, é controlada (aparentemente) pelos espectadores. É a luz que torna a imagem possível, no palco e no corpo. Se Respiração + enfatizava a materialidade e a maquinaria do corpo, $L u z$ - evidencia sua natureza etérea. $\mathrm{O}$ foco recai, então, no fato de que toda percepção é imagística, se não imag(em)inária.

O segundo ambiente é uma casa, um prisma retangular feito de tijolos aparentes, também recobertos por textos de Beckett. Ao longo das paredes externas, os espectadores podem olhar através de pequenas frestas e assistir a vídeos em tempo real (novamente imagens) da galeria, a partir dos diversos ângulos das câmeras de segurança.

$\mathrm{O}$ interior forrado de vidraças escuras é o terceiro ambiente. Aqui a plateia assiste a um vídeo em preto e branco de um personagem fechando janelas para impedir a invasão da luz que ameaça extinguir sua própria imagem, já que ele é apenas uma projeção de luz. Quando lâmpadas a vapor são acesas na sala, a imagem do personagem desaparece e os espectadores se deparam com seu próprio reflexo nas paredes. Eles (os sujeitos) substituíram o que parecia ser o "personagem" (o objeto). 
O quarto ambiente é uma maquete de vidro de uma casa, em cima de uma mesa. Imagens projetadas são então refletidas na maquete de vidro e nas paredes da sala. Em outra parte da instalação, a plateia é convidada a depositar seus próprios objetos, em geral, mas não só, fotografias, lembranças cujo valor sentimental só existe para eles mesmos. A plateia se move pela instalação, se demora, examina, lê as imagens nas paredes ou as palavras de Beckett na superfície ou dentro das caixas e nas paredes, palavras que ganham materialidade quando obras completas são esculpidas em blocos de madeira. A instalação é assim um prefácio ou poslúdio da encenação das peças em exibição, de forma que a própria peça, uma vez encenada, já é uma repetição, um eco, um duplo, a persistência de uma imagem.

Todos os projetos beckettianos dos Irmãos Guimarães foram apresentados junto com performances, em fevereiro e março de 2008, no Espaço Cultural Oi Futuro, no Rio de Janeiro, e essa foi sua quarta obra tendo como base as peças curtas de Beckett. A temporada, que marcou os dez anos de trabalho dos Irmãos Guimarães com (ou através de) Beckett, foi construída em torno de três conjuntos de performances elaboradas a partir da menor peça de Beckett, Respiração, trazida agora para primeiro plano. Em um período de dois meses no Oi Futuro, eles encenaram três conjuntos das obras de Beckett com o título geral, Resta Pouco a Dizer: Peças Curtas de Beckett por Adriano e Fernando Guimarães. A seus primeiros trabalhos, mencionados aqui, foi incorporado Improviso de Ohio, cujas primeiras palavras foram usadas no título, Resta Pouco a Dizer, com o célebre ator e diretor Aderbal Freire-Filho (fundador do Grêmio Dramático Brasileiro em 1973) no papel do Leitor e Willian Ferreira, fiel escudeiro da companhia, no papel do Ouvinte. Neste mesmo momento, Aderbal Freire-Filho estava dirigindo Hamlet, com Wagner Moura no papel título, para estrear em junho.

\section{O futuro das encenações de Beckett}

Os proprietários dos direitos de Beckett vêm tentando restringir, senão domar ou subjugar, uma obra de arte recalcitrante, insistindo em montagens fiéis e precisas, critérios que ninguém parece capaz de definir. Ao mesmo tempo em que se multiplicam as restrições impostas às montagens, um criativo grupo de diretores e artistas resiste, oferecendo a Beckett um novo caminho, uma terceira via, com atos radicais de imaginação, desdobrando o texto autorizado, objeto que pertence legalmente a alguém, agora transformado em ready-made, dentro de um novo contexto: em vitrines de lojas, fachadas de prédios abandonados ou desativados, ou em instalações em museus. Dessa forma, eles afirmam a heterogeneidade da encenação beckettiana sem violar os ditames de contratos firmados com os proprietários dos direitos. "É exatamente aqui que se encontra o Beckett que se manterá em cena no novo século", declara Fintan O'Toole ao discutir a questão da fidelidade aos textos de Beckett em um novo contexto. Ele nota, de forma significativa, que "as traduções meramente eficientes daquilo que se acredita serem as intenções do grande homem irão se esvair e desaparecer em uma obscuridade tediosa. As montagens que possibilitarem aos espectadores sentir o espírito de sofrimento e sobrevivência do nosso tempo conhecerão a eternidade de re-imaginações sem fim".

O redirecionamento que proponho aqui fica evidente na montagem de 2007 de Esperando Godot do Teatro Clássico do Harlem, dirigida por Christopher McElroen, com um 
elenco totalmente composto por negros, apresentando Wendell Pierce e J. Kyle Manzay, ambos de Nova Orleans. O texto foi primeiramente encenado no teatro do Harlem, em 2006, com um cenário que simulava um telhado de Nova Orleans. Em novembro de 2007, a peça foi encenada nas ruas do $9^{\circ}$ Distrito de Nova Orleans, a área mais devastada pelo furacão Katrina. As apresentações gratuitas ocorreram nos dias 2, 3, 9 e 10 de novembro (embora a montagem dessa apresentação "gratuita" tenha custado cerca de US\$200.000,00). Ao escrever para o Times-Picayune em 9 de novembro de 2007, David Cuthbert notou que "já faz muito tempo que Godot não é mais considerado 'um mistério envolvo em um enigma', como descreveu Brooks Atkinson em sua famosa crítica de 1956 para o New York Times depois da estreia na Broadway”. E Cuthbert segue, relembrando o Godot de 1957 em San Quentin: "provavelmente nunca mais veremos uma montagem mais acessível, mais engraçada, mais tocante e significativa que o Godot de Christopher McElroen. Ela é nossa, fala conosco diretamente, em falas e situações que sempre estiveram ali, mas que agora assumem uma nova ressonância".

Montagens como as do Teatro Clássico do Harlem, dos Irmãos Guimarães, de Atom Egoyan e de JoAnne Akailitis, entre outros, oferecem uma abordagem às re-imaginações necessárias a uma arte viva. A outra alternativa possível é apresentar a obra de Beckett como aquilo que ela pode, sem dúvida, já haver se tornado: uma curiosidade dentro de uma vitrine, uma peça bem guardada do Museu do Modernismo, montagens sem desvios (a não ser, talvez, deterioração), realizadas exatamente como foram escritas (pelo menos em alguma versão hipotética). Mas, mesmo nesse caso, como mostrei anteriormente, mesmo uma apresentação assim poderia ser re-imaginada e radicalmente modificada em um novo ambiente, em um espaço alternativo. Como, por exemplo, a montagem simbólica dirigida por Susan Sontag em uma Sarajevo sitiada, ou um grupo japonês de teatro que filmou seu Godot em uma estrada no interior, com as imensas chaminés da usina nuclear de Fukushima Daiichi ao fundo, a uma distância de não mais que $20 \mathrm{~km}$. Como relatou o jornalista do Wall Street Journal em 16 de agosto de 2011, “A versão [de Godot] filmada pelo grupo de teatro Kamone Machine começa com uma tomada de 30 segundos da barreira da zona de evacuação em torno da usina devastada e das estradas destruídas pela força do terremoto e do tsunami de 2011".

Se a cena teatral beckettiana se transformou em um campo de batalha onde ocorrem disputas políticas e jurídicas, onde os direitos de propriedade se sobrepõem à integridade artística ou aos valores estéticos, esses diretores, inspirados pelo compromisso do próprio Beckett com a vanguarda, por seus comentários sobre o teatro e pela estética desenvolvida em suas últimas peças, encontraram sua liberdade de expressão, a liberação de sua imaginação, abandonando ou ultrapassando o espaço contestado que chamamos teatro para outro mais expressivo. Eles desenvolveram uma arte híbrida, trazendo Beckett junto com eles, levando-a para o lugar ao qualo autor sempre acreditou que ela pertencia, junto às artes plásticas. $\mathrm{O}$ teatro de Beckett toma então outra direção, a direção de um novo século.

Tradução: Cláudia Soares Cruz 